\title{
АНТАГОНИЗМ ГЛИЦИНА И ГАЛОГЕНИД-ИОНОВ ПРИ ЛОКАЛЬНОЙ ДЕПАССИВАЦИИ МЕДИ В ЩЕЛОЧНЫХ РАСТВОРАХ
}

\author{
(C) 2018 М. Ю. Санина ${ }^{1}$, С. А. Калужина ${ }^{2}$, Н. Г. Нафикова ${ }^{2}$, Ю. В. Бердышева ${ }^{2}$, Е. В. Орлова \\ ${ }^{1}$ Воронежский государственный педагогический университет, ул. Ленина, 86, 394043 Воронеж, Россия \\ ${ }^{2}$ Воронежский государственный университет, Университетская пл., 1, 394018 Воронеж, Россия \\ ${ }^{3}$ Воронежский государственный медицинский университет им. Н. Н. Бурденко, \\ ул. Студенческая, 10, 394036 Воронеж, Россия \\ e-mail:smaria@mail.ru
}

Поступила в редакцию 09.04.2018

\begin{abstract}
Аннотация. В настоящей работе с использованием комплекса физико-химических методов проведен сравнительный анализ влияния анионного состава электролита на процессы локальной активации меди в щелочно-глицинатном растворе. Показано взаимовлияние органического (глицина) и неорганических $(\mathrm{NaBr}, \mathrm{NaF})$ депассиваторов, проявляющееся в эффекте антагонизма их действия, характер которого зависит от природы галогенид-ионов и наблюдается в широкой зоне концентраций.
\end{abstract}

Ключевые слова: медь, пассивность, локальная активация, щелочные среды, органические и неорганические активаторы.

DOI: https://doi.org/10.17308/kcmf.2018.20/518

\section{ВВЕДЕНИЕ}

Интерес к электрохимическому и коррозионному поведению меди обусловлен ее особенностью подвергаться в водных растворах, содержащих различные неорганические анионы, опасным видам локальных поражений, в частности, питтингообразованию при высокой общей коррозионной стойкости, тепло- и электропроводности. Вместе с тем, развитие новых технологий в области биоматериалов, биосенсоров и биокатализа актуализирует изучение взаимодействий в системе биологически-активные вещества (особенно аминокислоты) / неорганические анионы-активаторы / металл. В электролитах, содержащих как органические, так и неорганические депассиваторы, микродобавки последних способны вызывать ингибирование локального поражения поверхности металла [1-3]. Подобный эффект антагонизма двух активаторов может быть оценен с использованием принятых в теории жестких и мягких кислот и оснований (ЖМКО) Пирсона характеристик соединений и ионов (основность, поляризуемость, гидрофобность) [4]. Согласно данной теории «мягкие» кислоты, такие как незаряженные атомы металлов, координируются в первую очередь с «мягкими» основани- ями, например, с крупными органическими ионами, а вытеснение их из поверхностных соединений «жесткими» нуклеофильными частицами затрудняется. Так в $[2,5]$ показано, что в щелочном электролите присутствие глицина в количестве $5 \cdot 10^{-3} \mathrm{M}$ вызывает локальное поражение меди при потенциале $0.100 \mathrm{~B}$, введение $\left(1 \cdot 10^{-6}-1 \cdot 10^{-4}\right) \mathrm{M} \mathrm{NaCl}$ обусловливает повышение потенциала питтингообразования и, следовательно, затруднение депассивации меди, а при $\mathrm{c}(\mathrm{NaCl})>1 \cdot 10^{-4} \mathrm{M}$ их ингибирующее действие нивелируется. Торможение процесса локальной активации малыми количествами $\mathrm{Cl}^{-}$ -ионов объясняется, с одной стороны, снижением растворимости адсорбированного аминокислотного комплекса меди (II) за счет замещения молекул воды его гидратной оболочки $\mathrm{Cl}^{-}$-ионами. А с другой - возможностью образования малорастворимого нейтрального соединения $\mathrm{CuCl}$.

В продолжение предыдущих исследований [2, 5] целью настоящей работы являлось рассмотрение процесса депассивации меди в щелочном растворе при совместном присутствии органического (глицина (Gly)) и неорганических (бромид- и фторид-ионов) активаторов, а также выявление общих закономерностей и специфических особенностей 
взаимовлияния галогенид-ионов и глицина на локальную активацию меди.

\section{МЕТОДИКА ЭКСПЕРИМЕНТА}

Объектом исследования являлась медь (99.9 \%). В качестве рабочих использовали щелочно-глицинатные растворы с добавками активирующих неорганических анионов: $1 \cdot 10^{-2} \mathrm{M} \mathrm{NaOH}+5 \cdot 10^{-3} \mathrm{M}$ $\mathrm{Gly}+\mathrm{X} \mathrm{M} \mathrm{NaBr}$ и $1 \cdot 10^{-2} \mathrm{M} \mathrm{NaOH}+5 \cdot 10^{-3} \mathrm{M} \mathrm{Gly}+$ $\mathrm{X} \mathrm{M} \mathrm{NaF} \mathrm{(где} \mathrm{X}$ - концентрация неорганической добавки, варьирующая от $1 \cdot 10^{-6}$ до $1 \cdot 10^{-1} \mathrm{M}$ при $\mathrm{pH}=12$ ).

Эксперименты осуществляли на стационарном электроде с использованием классической электролитической трехэлектродной ячейки со свободным доступом воздуха при температуре $20 \pm 2{ }^{\circ} \mathrm{C}$.

Для получения достоверных результатов применяли комплекс физико-химических методов: вольтамперометрию, хроноамперометрию, оптическую и сканирующую электронную микроскопию (СЭМ) с последующим рентгеноспектральным микроанализом (РСМ) состава пассивного слоя на меди с помощью энергодисперсионной приставки к микроскопу (JEOL JSM-6510LV).

Перед проведением эксперимента механически полированные электроды подвергали катодной предполяризации в рабочем растворе при потенциале -1.000 В в течение 10 мин (для восстановления естественных оксидов и достижения воспроизводимости начального состояния поверхности металла). В дальнейшем проводили снятие циклических вольтамперограмм (ЦВА) (интервал потенциалов: от -1.000 В до + 1000 В). Электродные потенциалы меди измеряли относительно потенциала хлоридсеребряного электрода и пересчитывали на шкалу нормального водородного электрода.

\section{РЕЗУЛЬТАТЫ И ОБСУЖДЕНИЕ}

\section{1. Медь в щелочно-глицинатном электролите с бромидом натрия}

ЦВА меди в растворе $1 \cdot 10^{-2} \mathrm{M} \mathrm{NaOH}+5 \cdot 10^{-3} \mathrm{M}$ $\mathrm{Gly}+\mathrm{X} \mathrm{M} \mathrm{NaBr}$ с ростом концентрации $\mathrm{NaBr}$ от $1 \cdot 10^{-6}$ до $1 \cdot 10^{-3} \mathrm{M}$ не претерпевают существенных изменений по сравнению с ЦВА в щелочно-гицинатном растворе без добавок [2] и характеризуются наличием 3-х анодных и 2-х катодных пиков, обусловленных образованием соединений: $\mathrm{A} 1 / \mathrm{K} 1-\mathrm{Cu} /$ $\mathrm{Cu}_{2} \mathrm{O}, \mathrm{A} 2 / \mathrm{K} 2-\mathrm{Cu}_{2} \mathrm{O} / \mathrm{CuO}, \mathrm{Cu}(\mathrm{OH})_{2}, \mathrm{~A} 3-\mathrm{CuGly}^{+}$, $\mathrm{Cu}(\mathrm{Gly})_{2}[4,6]$ (рис. 1).

Микроскопические наблюдения поверхности медного электрода, проведенные после снятия ЦВА, фиксируют локальные поражения в виде небольшого количества мелких питтингов (ПТ) (рис. 2a), которые проявляются, согласно хроноамперометрическим данным, при $E=0.360 \mathrm{~B}$. Отсутствие локальных поражений при $E<0.360$ В мо-

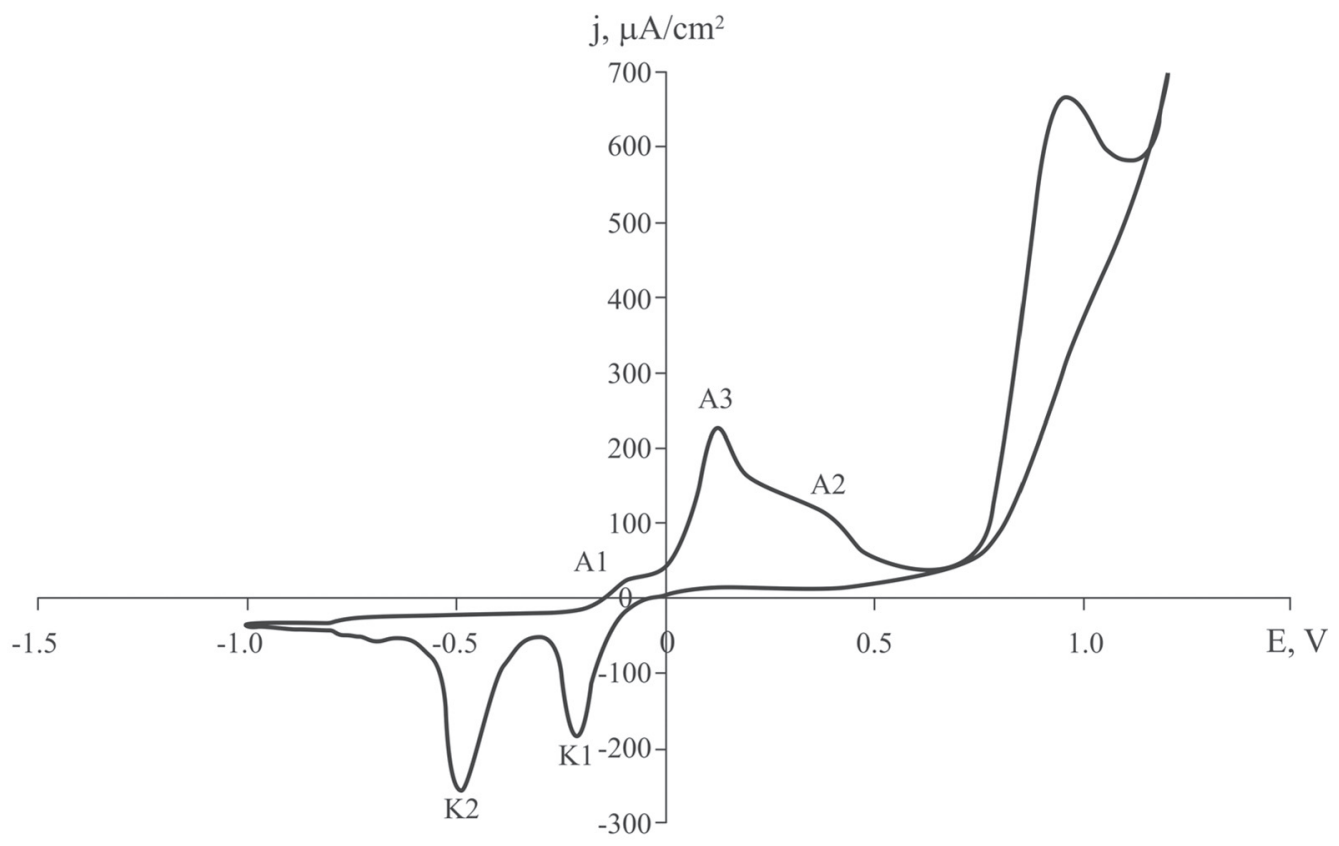

Pис. 1. ЦВА меди в растворе $1 \cdot 10^{-2} \mathrm{M} \mathrm{NaOH}+5 \cdot 10^{-3} \mathrm{M} \mathrm{Gly}+1 \cdot 10^{-3} \mathrm{M} \mathrm{NaBr}$, где $\mathrm{A} 1 / \mathrm{K} 1-\mathrm{Cu} / \mathrm{Cu}_{2} \mathrm{O}$, $\mathrm{A} 2 / \mathrm{K} 2-\mathrm{Cu}_{2} \mathrm{O} / \mathrm{CuO}, \mathrm{Cu}(\mathrm{OH})_{2}, \mathrm{~A} 3-\mathrm{CuGly}^{+}, \mathrm{Cu}(\mathrm{Gly})_{2}$

[Fig. 1. Cyclic voltammogram of copper in solution $1 \cdot 10^{-2} \mathrm{M} \mathrm{NaOH}+5 \cdot 10^{-3} \mathrm{M}$ Gly $+1 \cdot 10^{-3} \mathrm{M} \mathrm{NaBr}$. $\left.\mathrm{A} 1 / \mathrm{K} 1-\mathrm{Cu} / \mathrm{Cu}_{2} \mathrm{O}, \mathrm{A} 2 / \mathrm{K} 2-\mathrm{Cu}_{2} \mathrm{O} / \mathrm{CuO}, \mathrm{Cu}(\mathrm{OH})_{2}, \mathrm{~A} 3-\mathrm{CuGly}^{+}, \mathrm{Cu}(\mathrm{Gly})_{2}\right]$ 


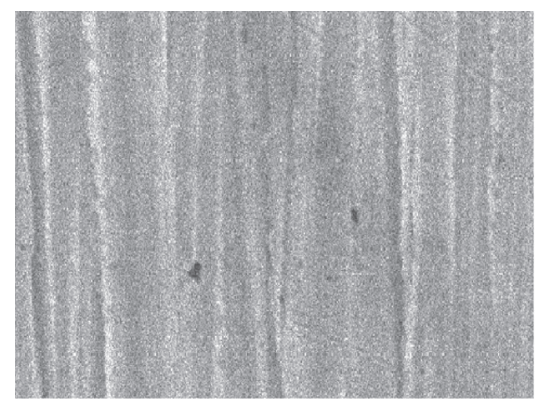

$a$

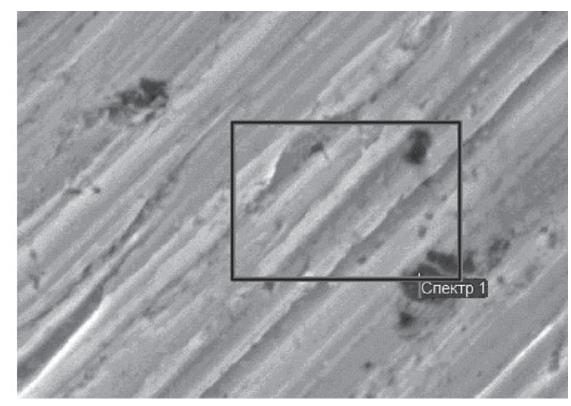

$b$

Рис. 2. Микрофотография поверхности меди (×2000) в растворе $1 \cdot 10^{-2} \mathrm{M} \mathrm{NaOH}+5 \cdot 10^{-3} \mathrm{M} \mathrm{Gly}+\mathrm{X} \mathrm{M} \mathrm{NaBr}$ $\left(\mathrm{X}=1 \cdot 10^{-3}(a) ; 1 \cdot 10^{-1}(b)\right)$

[Fig. 2. Microphotography of the copper surface $(\times 2000)$ in solution $1 \cdot 10^{-2} \mathrm{M} \mathrm{NaOH}+5 \cdot 10^{-3} \mathrm{M} \mathrm{Gly}+\mathrm{X} \mathrm{M} \mathrm{NaBr}$ $\left.\left(\mathrm{X}=1 \cdot 10^{-3}(a) ; 1 \cdot 10^{-1}(b)\right)\right]$

жет быть связано с адсорбцией бромид-ионов на активных центрах поверхности, препятствующей адсорбции глицина, а следовательно, и формированию ПТ. Результаты СЭМ и РСМ поверхности меди после снятия анодной поляризационной кривой (АПК) в растворе с добавкой $1 \cdot 10^{-3} \mathrm{M} \mathrm{NaBr}$ показывают, что пленка на поверхности электрода состоит из кислородных соединений меди (96.76 \% $\mathrm{Cu} ; 3.24 \%$ O) без включений фазы $\mathrm{CuBr}$.

При переходе к более высоким концентрациям неорганического активатора $\left(1 \cdot 10^{-2} \div 1 \cdot 10^{-1} \mathrm{M}\right)$ форма ЦВА (рис. 3) несколько меняется - на анодном участке появляется пик А4 в области потенциалов
$0.200 \div 0.250$ В, связанный с формированием труднорастворимого соединения $\mathrm{CuBr}(E=0.230 \mathrm{~B})$ $\left(\mathrm{pK}_{\mathrm{s}}=8.28\right)$ [7], препятствующего адсорбции органического активатора Gly-. Вместе с этим, на ЦВА появляется петля гистерезиса анодных токов, а микроскопические данные фиксируют на поверхности электрода ПТ (рис. 2b).

Исследование методами СЭМ и РСМ состава пленки на поверхности меди в растворе с $1 \cdot 10^{-1} \mathrm{M}$ $\mathrm{NaBr}$ после АПК показало наличие в ней элементов $\mathrm{O}, \mathrm{Cu}$ и $\mathrm{Br}(4.46 ; 92.90 ; 2.64$ \% соответственно), то есть элементный состав пленки претерпевает изменения относительно такового в системе

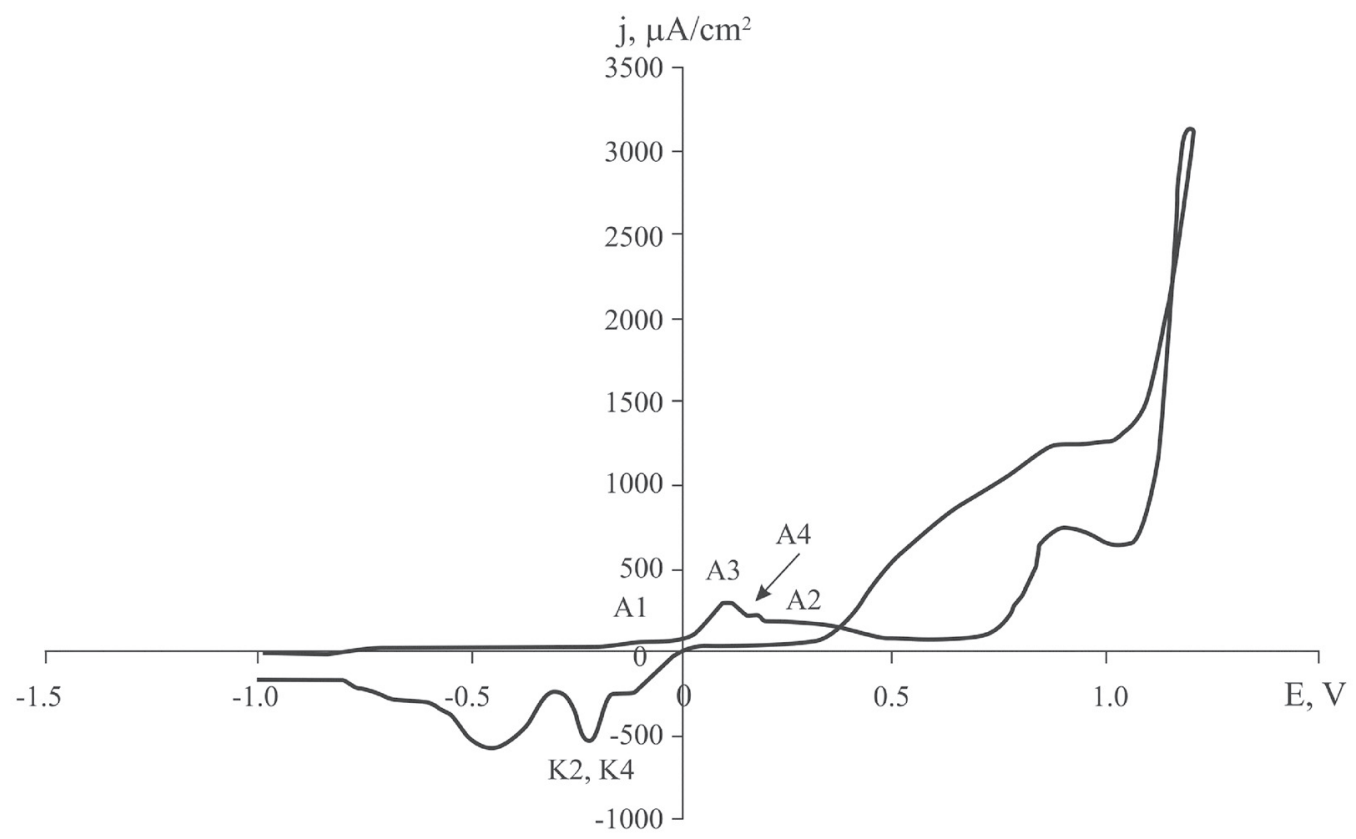

Рис. 3. ЦВА меди в растворе $1 \cdot 10^{-2} \mathrm{M} \mathrm{NaOH}+5 \cdot 10^{-3} \mathrm{M} \mathrm{Gly}+1 \cdot 10^{-1} \mathrm{M} \mathrm{NaBr}$, где $\mathrm{A} 2 / \mathrm{K} 2-\mathrm{Cu}_{2} \mathrm{O} / \mathrm{CuO}, \mathrm{Cu}(\mathrm{OH})_{2}, \mathrm{~A} 3-\mathrm{CuGly}^{+}, \mathrm{Cu}(\mathrm{Gly})_{2}, \mathrm{~A} 4 / \mathrm{K} 4-\mathrm{CuBr} / \mathrm{CuO}, \mathrm{Cu}(\mathrm{OH})_{2}$

[Fig. 3. Cyclic voltammogram of copper in solution $1 \cdot 10^{-2} \mathrm{M} \mathrm{NaOH}+5 \cdot 10^{-3} \mathrm{M} \mathrm{Gly}+1 \cdot 10^{-1} \mathrm{M} \mathrm{NaBr}$. $\left.\mathrm{A} 2 / \mathrm{K} 2-\mathrm{Cu}_{2} \mathrm{O} / \mathrm{CuO}, \mathrm{Cu}(\mathrm{OH})_{2}, \mathrm{~A} 3-\mathrm{CuGly}^{+}, \mathrm{Cu}(\mathrm{Gly})_{2}, \mathrm{~A} 4 / \mathrm{K} 4-\mathrm{CuBr} / \mathrm{CuO}, \mathrm{Cu}(\mathrm{OH})_{2}\right]$ 
с микродобавками $\mathrm{NaBr}$. При этом на поверхности металла наблюдаются четко выраженные ПТ (рис. $2 b$ ), и бромосодержащие соединения фиксируются лишь в них. Этот факт коррелирует с литературными данными [8] и свидетельствует, что локальная активация (ЛА) меди в изучаемой системе происходит, вероятно, по модели галогенидных зародышей Т. Окада [9], согласно которой ПТ - это результат первичного формирования малорастворимых галогенидных зародышей металла на пассивирующей пленке, последующего их прорастания в направлении границы пленка/металл и растворения металла вследствие транспорта частиц сквозь галогенид, ионная проводимость которого выше, чем у оксида.

Значения потенциала ЛА $\left(E_{\text {ЛА }}\right)$, полученные хроноамперометрическим методом в растворах с различным содержанием $\mathrm{NaBr}$, свидетельствуют, что зависимость $E_{\text {ЛА }}=f\left(\lg c_{\mathrm{Br}}\right)$ имеет вид перевернутой $\mathrm{V}$-образной кривой (рис. 4) и отражает эффект антагонизма действия двух активаторов - органического (глицина) и неорганического $\left(\mathrm{Br}^{-}\right)$. Суть его выражается в подавлении ЛА, вызванной добавкой аминокислоты, малыми количествами галогенидионов и изменением соотношения её интенсивности в пользу действия неорганического активатора при его высоких концентрациях [10]. Так, в диапазоне концентраций $1 \cdot 10^{-6} \mathrm{M} \div 1 \cdot 10^{-3} \mathrm{M} \mathrm{NaBr}$ наблюдается повышение стойкости меди к ЛА и облагораживание $E_{\text {ЛА }}$ до $0.360 \mathrm{~B}$ в растворе с добавкой $1 \cdot 10^{-3} \mathrm{M} \mathrm{NaBr}$. При дальнейшем увеличении концентрации $\mathrm{NaBr}$ эффект антагонизма двух активаторов снижается, что сопровождается разблагораживанием $E_{\text {ЛА }}$ до $0.170 \mathrm{~B}$.

Обнаруженные изменения $E_{\text {лА }}$ меди аналогичны таковым в системах с хлорид-ионами [2] и выражены более ярко, что коррелирует с представлениями о «жестко-мягких» взаимодействиях при образовании адсорбционных соединений меди, поскольку в ряду галогенид-ионов $\mathrm{F}^{-} \rightarrow \mathrm{Cl}^{-} \rightarrow \mathrm{Br}^{-} \rightarrow$ $\mathrm{I}^{-}$«жесткость» оснований уменьшается, а медь, как переходный металл, рассматривается в качестве мягкой кислоты. Таким образом, образующийся монобромид меди $\mathrm{CuBr}$ будет более устойчивым, чем аналогичные соединения меди с $\mathrm{F}^{-}$и $\mathrm{Cl}^{-}$-ионами, и интенсивнее будет препятствовать адсорбции аминокислоты.

Кроме того $\mathrm{Br}^{-}$-ионы в малых концентрациях могут вытеснять молекулы воды или $\mathrm{OH}^{-}$-ионы из адсорбционного комплекса на металле, делая его более гидрофобным и уменьшая растворимость в воде, что затрудняет активацию меди.

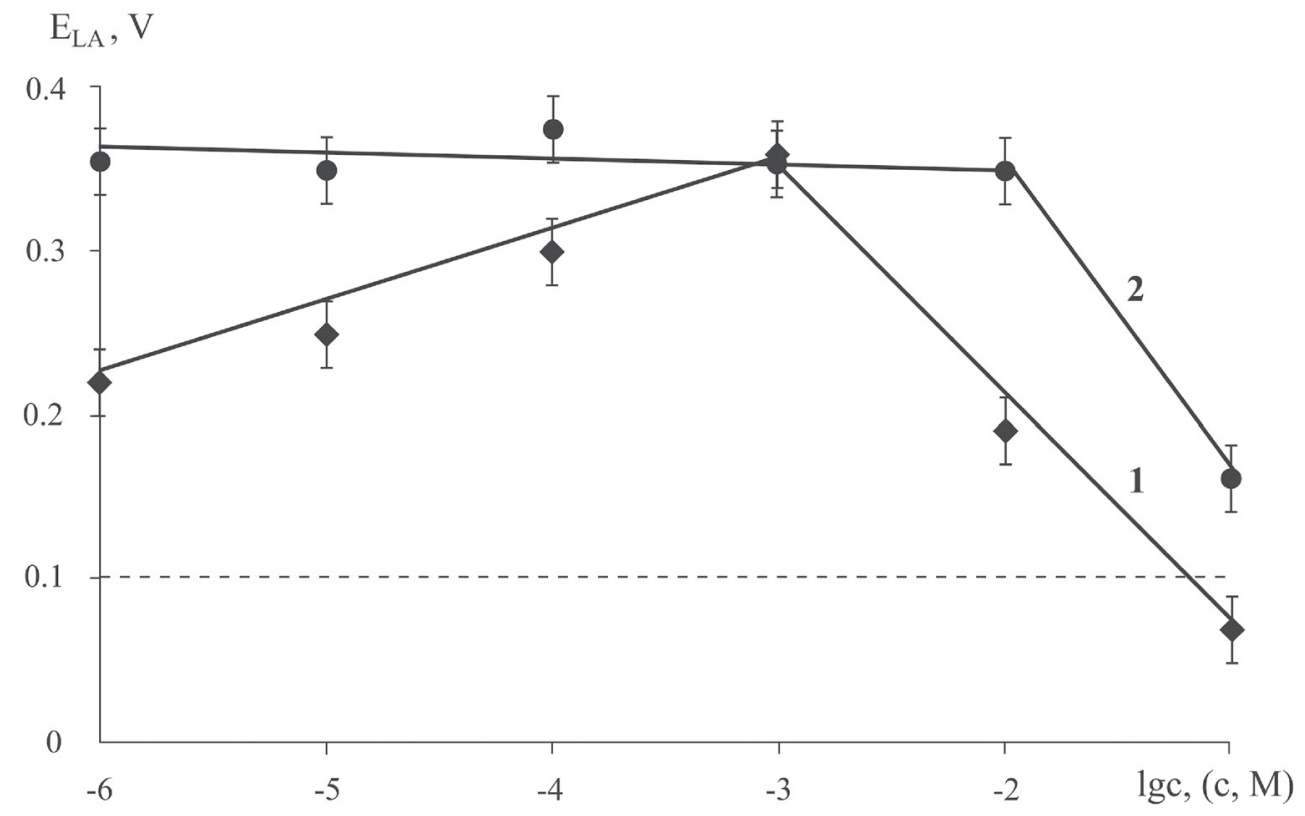

Рис. 4. Влияние концентрации бромид- (1) и фторид-ионов (2) на $E_{\text {лА }}$ меди в растворах $1 \cdot 10^{-2} \mathrm{M} \mathrm{NaOH}+5 \cdot 10^{-}$

${ }^{3} \mathrm{M}$ Gly $+\mathrm{X} \mathrm{M} \mathrm{NaHal,}\left(\mathrm{X}=1 \cdot 10^{-6} \div 1 \cdot 10^{-1} \mathrm{M}\right)$. Пунктиром показано значение $E_{\text {ЛА }}$ меди в растворе $1 \cdot 10^{-2} \mathrm{M} \mathrm{NaOH}$ $+5 \cdot 10^{-3} \mathrm{M}$ Gly [5]

[Fig. 4. The effect of the concentration of bromide (1) and fluoride ions (2) on the local activation potential $\left(E_{\mathrm{LA}}\right)$ of copper in solutions $1 \cdot 10^{-2} \mathrm{M} \mathrm{NaOH}+5 \cdot 10^{-3} \mathrm{M}$ Gly $+\mathrm{X} \mathrm{M} \mathrm{NaHal},\left(\mathrm{X}=1 \cdot 10^{-6} \div 1 \cdot 10^{-1} \mathrm{M}\right)$. The dashed line shows the value of the $E_{\mathrm{LA}}$ of copper in solution $1 \cdot 10^{-2} \mathrm{M} \mathrm{NaOH}+5 \cdot 10^{-3} \mathrm{M}$ Gly [5]] 
Уменьшение явления антагонизма при $\mathrm{c}(\mathrm{NaBr})>1 \cdot 10^{-3} \mathrm{M}$ обусловлено, вероятно, полным вытеснением органического иона из поверхностного адсорбционного комплекса и изменением роли неорганической добавки, которая начинает выступать как основной активатор исследуемого процесса.

Полученные значения порядков реакции по бромид-ионам $n=0\left(C=1 \cdot 10^{-6} \mathrm{M} \div 1 \cdot 10^{-3} \mathrm{M}\right)$, либо $n=0.25\left(C=1 \cdot 10^{-3} \div 1 \cdot 10^{-1} \mathrm{M}\right)$, свидетельствуют о локальной активации меди в изученных электролитах по механизму нуклеофильного замещения диссоциативного типа [5].

\section{2. Медь в щелочно-глицинатном электролите с фторидом натрия}

Форма ЦВА меди в растворе $1 \cdot 10^{-2} \mathrm{M} \mathrm{NaOH}+$ $5 \cdot 10^{-3} \mathrm{M}$ Gly $+\mathrm{X} \mathrm{M} \mathrm{NaF}$ в диапазоне концентраций $\mathrm{NaF} 1 \cdot 10^{-6} \mathrm{M} \div 1 \cdot 10^{-4} \mathrm{M}$ не изменяется и оказывается сопоставимой с таковой в щелочно-глицинатных системах с микродобавками бромид-ионов. По данным микроскопических наблюдений на поверхности металла появляются локальные поражения в виде неглубоких ПТ (рис. $5 a$ ), которые фиксируются при $E_{\text {ЛА }}=(0.350 \div 0.375 \mathrm{~B})$. После снятия АПК на меди в электролите с $1 \cdot 10^{-4} \mathrm{M} \mathrm{NaF}$ обнаружены кислородные соединения меди (96.33 \% $\mathrm{Cu} ; 3.67 \% \mathrm{O}$ ).

При переходе к более высоким концентрациям $\mathrm{NaF}\left(1 \cdot 10^{-3} \mathrm{M} \div 1 \cdot 10^{-1} \mathrm{M}\right)$ в растворе на ЦВА меди появляется характерная петля гистерезиса анодных токов (рис. 6), а по данным СЭМ и РСМ под поверхностной пленкой $(94.38 \% \mathrm{Cu} ; 5.62 \% \mathrm{O})$ на меди зафиксировано присутствие многочисленных ПТ (рис. 5b).

Однако при такой значительной концентрации $\left(1 \cdot 10^{-1} \mathrm{M}\right)$ неорганического активатора в пленке

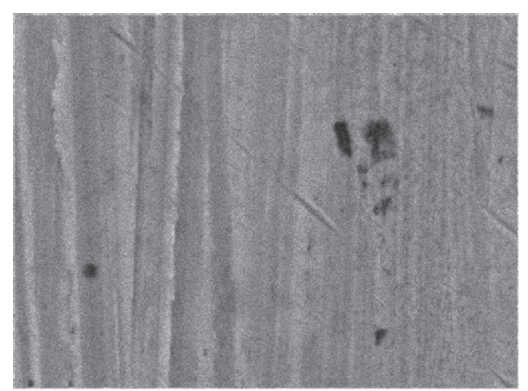

$a$ не было обнаружено присутствие галогена, в отличие от системы с такой же добавкой $\mathrm{NaBr}$. Установленный факт может быть объяснен большей «жесткостью» фторид-ионов как оснований, по сравнению с бромид-ионами, и, соответственно, меньшим сродством с «мягкой» кислотой - медью, из-за чего и не образуются ее соединения с фтором.

Экспериментальные значения $E_{\text {ЛА }}$, полученные хроноамперометрическим методом, показывают, что зависимость $E_{\text {ЛА }}=f\left(\lg C_{\mathrm{F}^{-}}\right)$в серии изученных растворов имеет вид (рис. 4), несколько отличающийся от аналогичного в системах с другими галогенидами. В последнем случае эффект антагонизма действия двух активаторов наблюдается в более широкой зоне концентраций фторида натрия $\left(1 \cdot 10^{-6} \div 1 \cdot 10^{-2} \mathrm{M}\right)$. Как видно из рис. 4 , при $C(\mathrm{NaF})<10^{-2} \mathrm{M} E_{\text {ЛА }}$ практически не изменяется, и лишь при $c(\mathrm{NaF})>10^{-2} \mathrm{M}$ начинается резкий спад потенциала ЛА, что сопровождается локальным поражением поверхности медного электрода и появлением ПТ. Таким образом, установленной концентрационной границей действия неорганического активатора $\mathrm{NaF}$ является $1 \cdot 10^{-2} \mathrm{M}$, что коррелирует с литературными данными [11], согласно которым фторид-ион является менее агрессивным активатором, чем бромид-ион, что подтверждает обнаруженную высокую концентрационную границу явления антагонизма действия органического и неорганического активаторов.

Как и в системах с бромид-ионами, порядок реакции по фторид-ионам оказывается значительно меньше единицы $(n=0.13)$, что свидетельствует о том, что и в последней системе ЛА меди протекает в соответствии с механизмом нуклеофильного замещения диссоциативного типа.

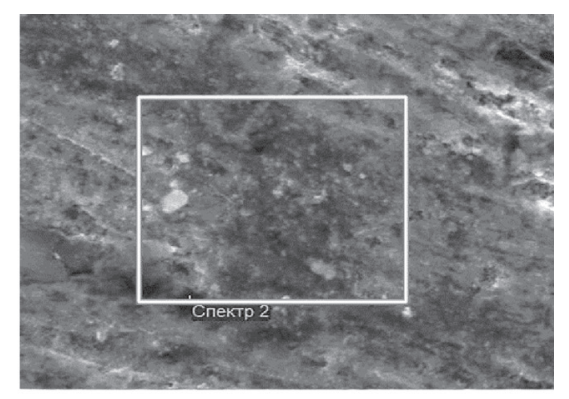

$b$

Рис. 5. Микрофотография поверхности меди (×2000) в растворе $1 \cdot 10^{-2} \mathrm{M} \mathrm{NaOH}+5 \cdot 10^{-3} \mathrm{M} \mathrm{Gly}+\mathrm{X} \mathrm{M} \mathrm{NaF}$ $\left(\mathrm{X}=1 \cdot 10^{-4}(a) ; 1 \cdot 10^{-1}(b)\right)$.

[Fig. 5. Microphotography of the copper surface $(\times 2000)$ in solution $1 \cdot 10^{-2} \mathrm{M} \mathrm{NaOH}+5 \cdot 10^{-3} \mathrm{M}$ Gly $+\mathrm{X} \mathrm{M} \mathrm{NaF}$ $\left.\left(\mathrm{X}=1 \cdot 10^{-4}(a) ; 1 \cdot 10^{-1}(b)\right)\right]$ 


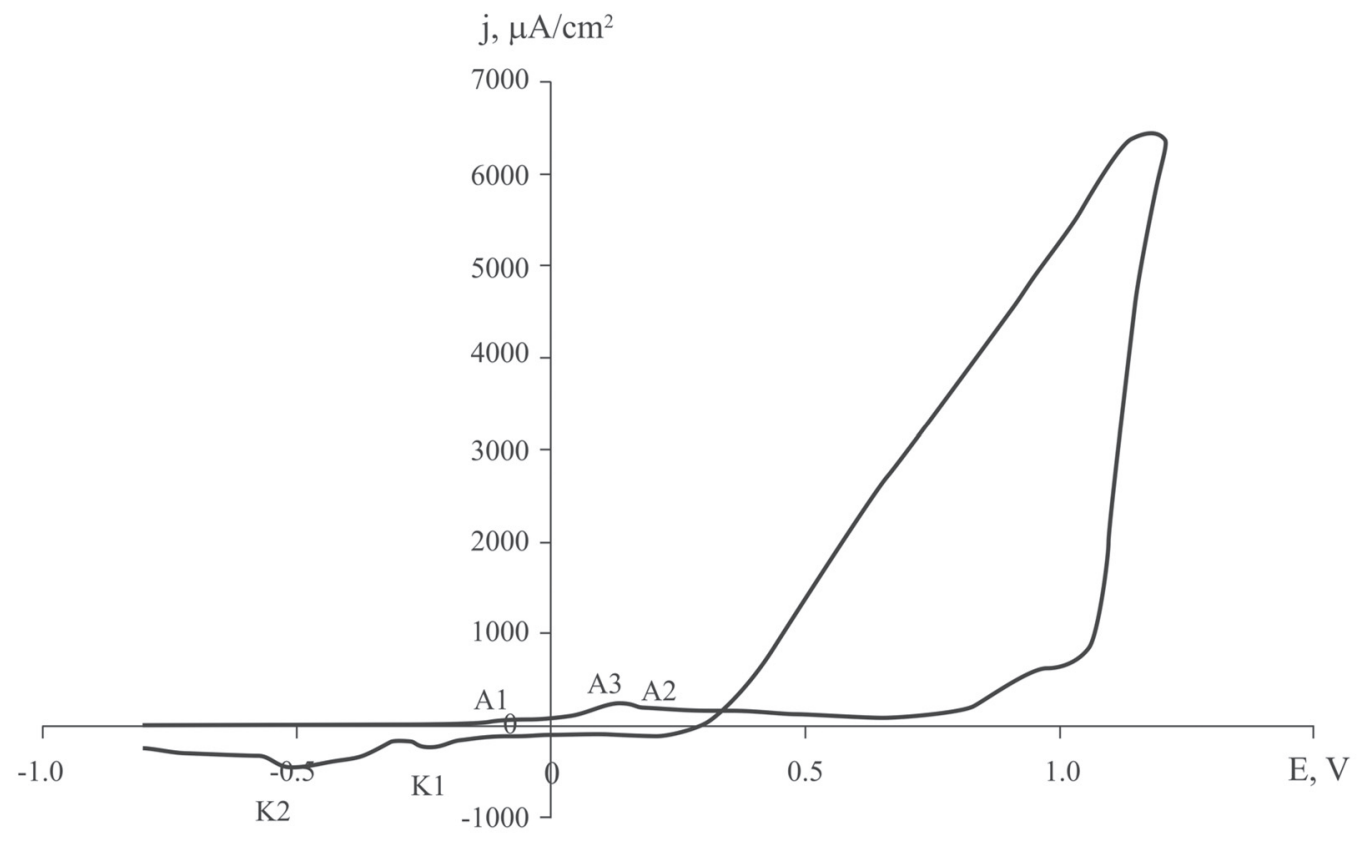

Рис. 6. ЦВА меди в растворе $1 \cdot 10^{-2} \mathrm{M} \mathrm{NaOH}+5 \cdot 10^{-3} \mathrm{M}$ Gly $+1 \cdot 10^{-1} \mathrm{M} \mathrm{NaF}$, где $\mathrm{A} 1 / \mathrm{K} 1-\mathrm{Cu} / \mathrm{Cu}_{2} \mathrm{O}, \mathrm{A} 2 / \mathrm{K} 2-\mathrm{Cu}_{2} \mathrm{O} / \mathrm{CuO}, \mathrm{Cu}(\mathrm{OH})_{2}, \mathrm{~A} 3-\mathrm{CuGly}^{+}, \mathrm{Cu}(\mathrm{Gly})_{2}$

[Fig. 6. Cyclic voltammogram of copper in solution $1 \cdot 10^{-2} \mathrm{M} \mathrm{NaOH}+5 \cdot 10^{-3} \mathrm{M}$ Gly $+1 \cdot 10^{-1} \mathrm{M} \mathrm{NaF}$. $\left.\mathrm{A} 1 / \mathrm{K} 1-\mathrm{Cu} / \mathrm{Cu}_{2} \mathrm{O}, \mathrm{A} 2 / \mathrm{K} 2-\mathrm{Cu}_{2} \mathrm{O} / \mathrm{CuO}, \mathrm{Cu}(\mathrm{OH})_{2}, \mathrm{~A} 3-\mathrm{CuGly}^{+}, \mathrm{Cu}(\mathrm{Gly})_{2}\right]$

\section{ЗАКЛЮЧЕНИЕ}

Действие $\mathrm{F}^{-}$- и $\mathrm{Br}^{-}$-ионов на локальную депассивацию меди в щелочно-глицинатном растворе имеет как общие, так и специфические особенности. В обеих системах реализуется механизм замещения диссоциативного типа $\left(S_{\mathrm{N}}\right)$ и проявляется эффект антагонизма активаторов. Отличия в поведении бромид- и фторид-ионов при локальной активации меди в изученных средах соответствуют представлениям о «жестко-мягких» взаимодействиях между компонентами электролита и металлом: более «мягкое» основание - бромидион, взаимодействуя с «мягкой» кислотой - медью, образует соединение, входящее в состав поверхностной пленки, в то время как более «жесткое» основание - фторид-ион не обнаруживается в ней. Кроме того, менее интенсивное «мягкожесткое» взаимодействие фторид-ионов с медью приводит к тому, что фторид-ионы предотвращают локальную активацию глицин-ионами в широкой области концентраций (до $\left.10^{-2} \mathrm{M}\right)$ и только при очень высоких концентрациях, где скорее они становятся не добавкой, а основной частью электролита, вызывают питингообразование.

\section{СПИСОК ЛИТЕРАТУРЫ}

1. Kaluzhina S. A., Skrypnikova E. A., Nikitchenko E. V., Vasilenko V. A. European Corrosion Conference: Long Term Prediction and Modelling of Corrosion, EUROCORR 2004, Abstracts, 12-16 September, 2004, Nice, France, 2004, p. 10.

2. Skrypnikova E. A., Kaluzhina S. A., Orlova E. V., Volkova L. N. // Int. J. Corros. Scale Inhib., 2013, 2, № 1, pp. 1-8. DOI: 10.17675/2305-6894-2013-2-1-001-008

3. Кузнецов Ю. И. Лукьянчиков О. А. // Электрохимия, 1987, т. 23, № 2, с. 1225-1231.

4. Кузнецов Ю. И. // Защита металлов, 1995, т. 31, № 3, c. 229-238.

5. Скрыпникова Е. А., Калужина С. А., Орлова Е. В. // Электрохимия, 2011 т. 47, № 11, с. 1315-1319.

6. Сурвила А. А., Уксене В. А. // Электрохимия, 1989, т. 25, № 7, с. 952-953.

7. Лурье Ю. Ю. Справочник по аналитической химии. М.: Химия, 1989, 448 с.

8. Калужина С. А., Кобаненко И. В. // Защита металлов, 2001, т. 37, №. 3, с. 266-273. DOI: 10.1023/ A: 1010494226972

9. Okada T. // J. Electrochem. Soc., 1984, vol. 131, № 2, pp. 241-247. DOI: $10.1149 / 1.2115556$

10. Кузнецов Ю. И. // Защита металлов, 2002, т. 38, № 2, с. 122-131.

11. Кузнецов Ю. И. // Успехи химии, 2004, т. 73, № 1, c. $79-93$. 


\title{
ANTAGONISM OF GLYCINE AND HALOGEN-IONS IN COPPER LOCAL DEPASSIVATION IN ALKALINE SOLUTIONS
}

\author{
(C) 2018 M. Yu. Sanina, S. A. Kaluzhina, N. G. Nafikova, Yu. V. Berdysheva, E. V. Orlova \\ ${ }^{1}$ Voronezh State Pedagogical University, 86 Lenin str., 394043 Voronezh, Russia \\ ${ }^{2}$ Voronezh State University, 1 Universitetskaya pl., 394018 Voronezh Russia \\ ${ }^{3}$ N.N. BurdenkoVoronezh State Medical University, 10 Studencheskaya str., 394036 Voronezh, Russia \\ e-mail: smaria@mail.ru
}

Recieved 09.04.2018

\begin{abstract}
The paper studies the influence of the nature and concentration of inorganic activators on the local activation of copper in an aqueous alkaline medium containing an organic activator, i.e glycine. The following solutions were used: $1 \cdot 10^{-2} \mathrm{M} \mathrm{NaOH}+5 \cdot 10^{-3} \mathrm{M}$ Gly $+\mathrm{X} \mathrm{M} \mathrm{NaBr}(\mathrm{NaF})$ $\left(\mathrm{X}=1 \cdot 10^{-6} \div 1 \cdot 10^{-1} \mathrm{M} ; \mathrm{pH}=12\right)$. The complex of physicochemical methods included voltammetry, chronoamperometry, scanning electron microscopy, and X-ray spectral microanalysis. It was established that both organic and inorganic additives cause the local activation of copper by the mechanism of nucleophilic substitution of a dissociative type. In the presence of $\mathrm{Br}^{-}$and $\mathrm{F}^{-}$ions the effect of activator antagonism appears in the studied systems. This is the effect of suppressing local damage of copper caused by glycine, small amounts of halide ions $\left(1 \cdot 10^{-6} \div 1 \cdot 10^{-3} \mathrm{M} \mathrm{NaBr}\right.$ and $1 \cdot 10^{-6} \div$ $\left.1 \cdot 10^{-2} \mathrm{M} \mathrm{NaF}\right)$. An increase in the concentration of $\mathrm{NaBr}$ to $1 \cdot 10^{-2} \mathrm{M}$ and $\mathrm{NaF}$ to $1 \cdot 10^{-1} \mathrm{M}$ weakens the antagonism of activators. In this case, the potential of local activation shifts towards negative values up to the values found in $1 \cdot 10^{-2} \mathrm{M} \mathrm{NaOH}+5 \cdot 10^{-3} \mathrm{M}$ Gly. The differences in the behaviour of $\mathrm{Br}$ and $\mathrm{F}^{-}$-ions with the local activation of copper in the studied media are explained from the standpoint of the Pearson's theory of hard and soft acids and bases. The "softer" base (Br) interacts more strongly with the "soft" acid $(\mathrm{Cu})$ and forms a surface compound $(\mathrm{CuBr})$. The "harder" base $\left(\mathrm{F}^{-}\right)$ does not become a part of the surface film. In addition, the less intense "soft-hard" interaction of $\mathrm{F}$ ions with copper leads to the fact that only at very high concentrations of $\mathrm{F}^{-}$do the ions cause the formation of pitting.
\end{abstract}

Keywords: copper, passivity, local activation, alkaline media, organic and inorganic activators.

DOI: https://doi.org/10.17308/kcmf.2018.20/518

\section{REFERENCES}

1. Kaluzhina S. A., Skrypnikova E. A., Nikitchenko E. V., Vasilenko V. A. In: Proceedings of European Corrosion Conference: Long Term Prediction and Modelling of Corrosion, EUROCORR 2004, Abstracts, 12-16 September, 2004, Nice, France, 2004, p. 10.

2. Skrypnikova E. A., Kaluzhina S. A., Orlova E. V., Volkova L. N. Int. J. Corros. Scale Inhib., 2013, vol. 2, no. 1, pp. 1-8. DOI: 10.17675/2305-6894-2013-2-1-001-008

3. Kuznetsov Y. I. Luk'yanchikov O. A. Jelektrohimija [Russian Journal of Electrochemistry], 1987, vol. 23, no. 9, pp. 1225-1231. (in Russ.)

4. Skrypnikova E. A., Kaluzhina S. A., Orlova E. V. Russian Journal of Electrochemistry, 2011, vol. 47, no. 11, pp. 1231-1235. DOI: 10.1134/S102319351110020X

5. Kuznetsov Y. I. Zashhita metallov [Protection of Metals], 1995, vol. 31, no. 3, pp. 229-238. (in Russ.)
6. Survila A. A., Uksene V. A. Jelektrohimija [Russian Journal of Electrochemistry], 1989, vol. 25, no. 7, pp. 952953. (in Russ.)

7. Lur'e Yu. Yu. Spravochnik po analiticheskoi khimii [Handbook of Analytical Chemistry]. Moscow, Khimiya Publ., 1989, 448 p. (in Russ.)

8. Kaluzhina S. A., Kobanenko I. V. Protection of Metals, 2001, vol. 37, no. 3, pp. 237-243. DOI: 10.1023/ A:1010494226972

9. Okada T. J. Electrochem. Soc., 1984, vol. 131, no. 2, pp. 241-247. DOI: 10.1149/1.2115556

10. Kuznetsov Y. I. Protection of Metals, 2002, vol. 38: no. 2, pp. 103-111. DOI: 10.1023/A:1014904830050

11. Kuznetsov Y. I. Russian Chemical Reviews, 2004, vol. 73, no. 1, pp. 75-87. DOI: 10.1070/RC2004v073n 01ABEH000864 
Санина Мария Юрьевна - к. х. н., доцент кафедры химии, Воронежский государственный педагогический университет; тел.: +7(473) 2554540, e-mail: smaria@mail.ru

Калужина Светлана Анатольевна - д. х. н., профессор кафедры физической химии химического факультета, Воронежский государственный университета; тел.: +7(473) 2208538, e-mail: svetlana.kaluzhina@gmail.com

Нафикова Наталья Геннадьевна - соискатель кафедры физической химии химического факультета, Воронежский государственный университет; тел.:+7(960) 1029268, e-mail: nng2110@mail.ru

Бердышева Юлия Владимировна - студент кафедры физической химии химического факультета, Воронежский государственный университет; тел.: +7(473) 2208538, e-mail: julechka_94_vrn@mail.ru

Орлова Евгения Валерьевна - к. х. н., преподаватель кафедры естественнонаучных и математических наук, Воронежский государственный медицинский университет им. Н.Н. Бурденко; тел.: +7(951) 761817, e-mail: zeoszes@mail.ru
Maria Yu. Sanina - Cand. Sci. (Chem.), Associate Professor, Chemistry department, Voronezh State Pedagogical University, tel.: +7(473) 2554540, e-mail: smaria@mail.ru

Svetlana A. Kaluzhina - Dr. Sci. (Chem.), Full Professor, Chemical Faculty, Physical Chemistry Department, Voronezh State University; tel.: +7(473) 2208538, e-mail: svetlana.kaluzhina@gmail.com

Natalia G. Nafikova - applicant, Physical Chemistry Department, Voronezh State University; tel.: +7(960) 1029268, e-mail: nng2110@mail.ru

Yuliya V. Berdysheva - student, Chemical Faculty, Physical Chemistry Department, Voronezh State University; tel.: +7 (473) 2208538, e-mail: julechka 94 vrn@mail.ru

Evgeniya V. Orlova-Cand. Sci. (Chem.), Lecturer, Department of Natural Sciences and Mathematical Sciences, N.N. Burdenko Voronezh State Medical University, tel.: +7(951) 761817, e-mail: zeoszes@mail.ru 